\title{
A Cable-Borne Tram for Atmospheric Measurements along Transects
}

\author{
S. P. ONClEy, K. SCHWENZ, S. P. BURnS,* AND J. Sun \\ National Center for Atmospheric Research, ${ }^{+}$Boulder, Colorado \\ R. K. MONSON \\ Department of Ecology and Evolutionary Biology, University of Colorado, Boulder, Colorado
}

(Manuscript received 24 April 2008, in final form 18 August 2008)

\begin{abstract}
A system to make atmospheric measurements from a moving trolley suspended by a stretched cable has been developed. At present, these measurements consist of wind velocity, temperature, humidity, and carbon dioxide concentration, though other sensors may be added. The track consists of cable segments attached to turns mounted on standard triangular towers. Using this approach, the path can be a closed (three dimensional) polygon of arbitrary length. This tool allows continuous, high spatial and temporal resolution sampling in environments, such as within forest canopies, not possible with other platforms. This system was used at the Niwot Ridge AmeriFlux site to obtain insight into the spatial and temporal structure of $\mathrm{CO}_{2}$, wind, and humidity fields in a natural forest ecosystem. Specifically, cool, moist, and $\mathrm{CO}_{2}$-rich air was observed to move in thin blobs downslope along the local water drainage through the subcanopy space at night.
\end{abstract}

\section{Introduction}

Since the real world is rarely homogeneous, sampling at multiple locations is required in order to determine quantities that represent the state of the atmosphere close to the earth's surface. Real-world inhomogeneities often exist over a wide range of spatial scales, especially for processes that involve multiple scientific disciplines (e.g., meteorology, biology, and hydrology). Furthermore, some of the spatial scales are dynamic and change with temporally varying quantities such as wind direction and atmospheric stability. Remote sensing methods can satisfy this sampling need in some situations (e.g., when long line-of-sight is available) and for some quantities (e.g., wind, temperature, etc.), but many applications remain that require in situ sampling and higher spatial resolution. Multiple towers can be

\footnotetext{
* Additional affiliation: Department of Ecology and Evolutionary Biology, University of Colorado, Boulder, Colorado.

+ The National Center for Atmospheric Research is sponsored by the National Science Foundation.

Corresponding author address: Steven P. Oncley, NCAR/EOL, P.O. Box 3000, Boulder, CO 80307-3000.

E-mail: oncley@ucar.edu
}

deployed, but their locations and thus the spatial scales that can be sampled are fixed. To address this sampling need, we have developed a sensor platform that traverses a track consisting of multiple cable segments.

Moving a sensor package among several locations has been done for many years and is required when only one sensor is available and/or when sufficient accuracy between independent sensors cannot be guaranteed. One such "roving probe" system was described by Miyake et al. (1970) in which a cup anemometer and dry and wet thermocouples were moved between several heights to obtain vertical profiles of wind speed, temperature, and humidity near the earth's surface. Cable-based trams have been operated traversing between two fixed supports. Dabberdt (1968) described a motor-driven "traveler" that moved an anemometer over a distance of $274 \mathrm{~m}$ between two fixed towers to study towerinduced wakes. Recent tram systems have been mostly used for radiation measurements. Baldocchi et al. (1984a,b), Lee and Black (1993), Chen et al. (1997), Privette et al. (1997), and Blanken et al. (2001) all put radiometers on platforms that moved under or just above forest canopies to create an average of upwelling and downwelling radiation representative of an area. Singh et al. (2008) have extended the traversing idea by deployed a winch on a horizontal cable that can 
TABLE 1. List of commercial products used in the TRAM system.

\begin{tabular}{lll}
\hline \multicolumn{1}{c}{ Type } & \multicolumn{1}{c}{ Part No. } & \multicolumn{1}{c}{ Manufacturer (city) } \\
\hline Sonic anemometer electronics & SATI & ATI (Longmont, CO) \\
Carbon dioxide gas analyzer & DX6100 & RMT (Moscow, Russia) \\
Pump & NMP05 & KNF Neuberger (Trenton, NJ) \\
Attitude sensor (fluxgate compass) & HMR3300 & Honeywell (Plymouth, MN) \\
Temperature/humidity & SHT75 & Sensiron (Zürich, Switzerland) \\
GPS receiver & Lassen SQ & Trimble Navigation (Sunnyvale, CA) \\
RFID reader and tags & TRR02OEM & Intersoft (Tullahoma, TN) \\
Radio modem & WIT2410 & Cirronet (Duluth, GA) \\
Towers & 25G & Rohn Industries (Peoria, IL) \\
Motor & E242 & Reliance Electric (Greenville, SC) \\
Power supply & GENSYS 750W & Lambda Americas (Neptune, NJ) \\
\hline
\end{tabular}

move a sensor package vertically and thus perform twodimensional sampling between two supports (e.g., of vertical and cross-stream specific conductivity profiles within a river). Gamon et al. (2006) put a spectral reflectometer on a motorized car that traversed back and forth along a 100-m straight track consisting of a pair of aluminum angles supported by multiple tripods.

The system described here is able to run along a closed path (a loop) and is able to measure both spatially varying wind velocity and scalar quantities (and thus scalar advection). The system has been designed so that multiple sensor packages could be operated simultaneously on the same path in order to reduce sampling errors. If wind is measured at more than two positions on a closed path, flow divergence could be calculated continuously.

One problem that appears to require this type of sampling is the quantification of carbon exchange in forest ecosystems. Forests in mountains in the western United States are important since they represent a significant part of the U.S. carbon sink (Schimel et al. 2002). During multiyear drought conditions, carbon uptake is primarily restricted to montane ecosystems, where the winter snowpack provides a reliable seasonal pulse of high water availability. However, to understand the processes that control net ecosystem exchange (NEE) in ecosystems with complex terrain requires observations at a variety of spatial and temporal scales.

Sun et al. (1998) present one case study showing evidence of subcanopy horizontal transport of $\mathrm{CO}_{2}$ in forests, associated with nocturnal drainage flows. More recently, experiments [the Niwot Ridge experiment (NIWOT02) and Airborne Carbon in the Mountains Experiment (ACME/CME04)] focusing on this problem have been carried out at the Niwot Ridge AmeriFlux site near the University of Colorado Mountain Research Station (CU/MRS), which have supplemented routine observations (Sun et al. 2007; Burns et al. 2009). The measurements at this site show that, although the abovecanopy winds are driven by the synoptic flow, the subcanopy flow is decoupled by the physical and thermal structure of the canopy. This subcanopy flow is buoyancy driven (upslope during the day and downslope at night) and generally follows the local slope. At night, there also was a tendency to converge toward the local water drainage (i.e., Como Creek). This convergence was seen by a nocturnal buildup of $\mathrm{CO}_{2}$ in the direction of the Creek, with horizontal gradients observed at scales of $100 \mathrm{~m}$.

Here we describe the first use of a new cable-based measurement platform at Niwot Ridge to determine if finer spatial and temporal scales are important in the subcanopy transport of $\mathrm{CO}_{2}$ and if Como Creek impacts this transport. We call our platform the Transect Measurement (TRAM) system.

\section{TRAM description}

Our TRAM system consists of four subsystems: the track, the trolley itself, sensor packages, and a data system. Each of these is described below. For reference, Table 1 lists the commercial components of this system. All other components were built by the National Center for Atmospheric Research (NCAR).

\section{a. Track}

The TRAM system is functionally like a toy electric train, with a trolley driven by an electric motor along a fixed, closed-loop track that also provides power to the motor. The majority of the TRAM track is segments of tensioned cable. There are two cables for each path segment-a 6.35-mm-diameter stainless steel "suspension cable" that supports the trolley and is the electrical ground connection and a 3.13-mm copper "power" cable. Since these cables obviously are straight (except for the catenary droop), "turns" fabricated from bent 


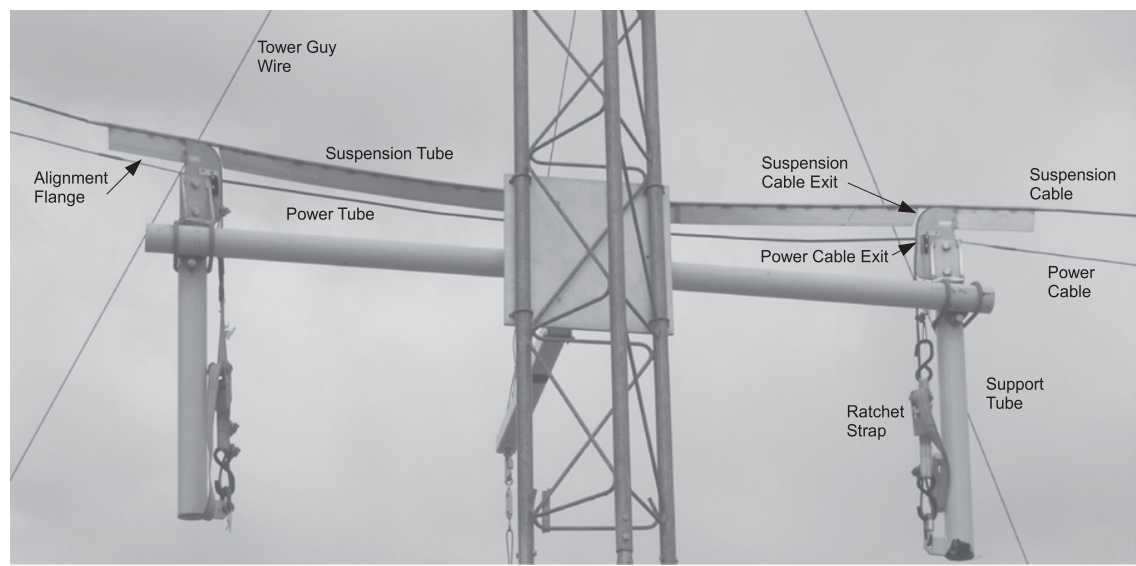

FIG. 1. One of the TRAM turns installed on a tower. Material that insulates the power cable after exiting the tubing was removed prior to taking this photograph for clarity.

tubing are required to make the track change direction (see Fig. 1). Cables from one track segment enter from one side and slip into the suspension and power tubing of the turn. After a short distance, the cables exit through slots in the tubing and are tensioned using ratchet straps to support tubes. A mirror image set up on the other side of the turn connects to the next cable segment. An alignment flange prevents the trolley from hitting the support tube as it negotiates the turn. The turns themselves are attached to a set of guyed towers.

The suspension cables were tensioned between 50 and $75 \mathrm{lbs}$. With this tension, the droop at the center of the cable was about $2 \%$ of the cable length $(0.3 \mathrm{~m}$ in a $15-\mathrm{m}$ run) when the trolley was on the cable. Also, the trolley pitch angle changed by up to $10^{\circ}$ while traversing a cable segment. Since the actual path is approximately repeatable with time and the droop was of the same order of magnitude as the variations in terrain height, these deviations from straight-line sampling were acceptable. For more demanding applications, more towers and/or somewhat higher tensions could be used.

\section{b. Trolley}

The trolley (Fig. 2) used in this study had two wheel clusters connected by a flexible link. (The link allows the trolley to negotiate turns.) There are five wheels in each cluster. Three press against the suspension cable from different directions to hold the cluster captive to the cable. The other two wheels follow a guide rail that is built into the turns to prevent the trolley from hitting structural elements while transiting the turn. All but the top suspension wheel in each cluster are mounted on spring-loaded pivots to adjust for the somewhat different diameters of the suspension cable and support tubing and to allow some "play" as the trolley follows each turn.
A DC motor is mounted to one side of the rear wheel cluster and is connected via a $90^{\circ} 2: 1$ reduction gear box to the topmost wheel of the cluster. Thus, the trolley is driven from the back along the suspension cable. A plastic box containing electronics (some instrumentation, the data system, and power conditioning) is mounted on the rear cluster on the opposite side of the wheel to offset the weight of the motor. Counterweights are added to one side or the other to adjust the balance. The motor and electronics box are mounted to the rear cluster so that the anemometer (mounted to the front wheel cluster) is as far as possible from objects causing flow blockage. If more carrying capacity (bulk or weight) were needed, more wheel clusters could be added.

Spring-loaded copper wheels attached ahead of the front cluster and behind the rear cluster roll along the suspension cable to provide the electrical contact to ground and to help align the trolley to the cable. Springloaded carbon brushes contact these wheels to complete the electrical connection. A spring-loaded copper clip slides along the power wire on a two-axis pivoting arm riding behind the trolley to provide the positive power connection to the trolley. At night, some small sparks have been observed from this slider connection, but sparks do not occur at the wheel contacts. During operation in extreme fire danger conditions, it may be necessary to change the power contact to use rollers as well.

Power is provided to the cables by connecting a bench-style power supply to one or more of the turns. (More than one connection can reduce the voltage drop.) With the motor and gearbox we are using, 30 VDC is needed to allow the trolley to negotiate all of the turns comfortably. The trolley uses about $7 \mathrm{~A}$ when running through the turns (due to greater drag) and 1-5 A 


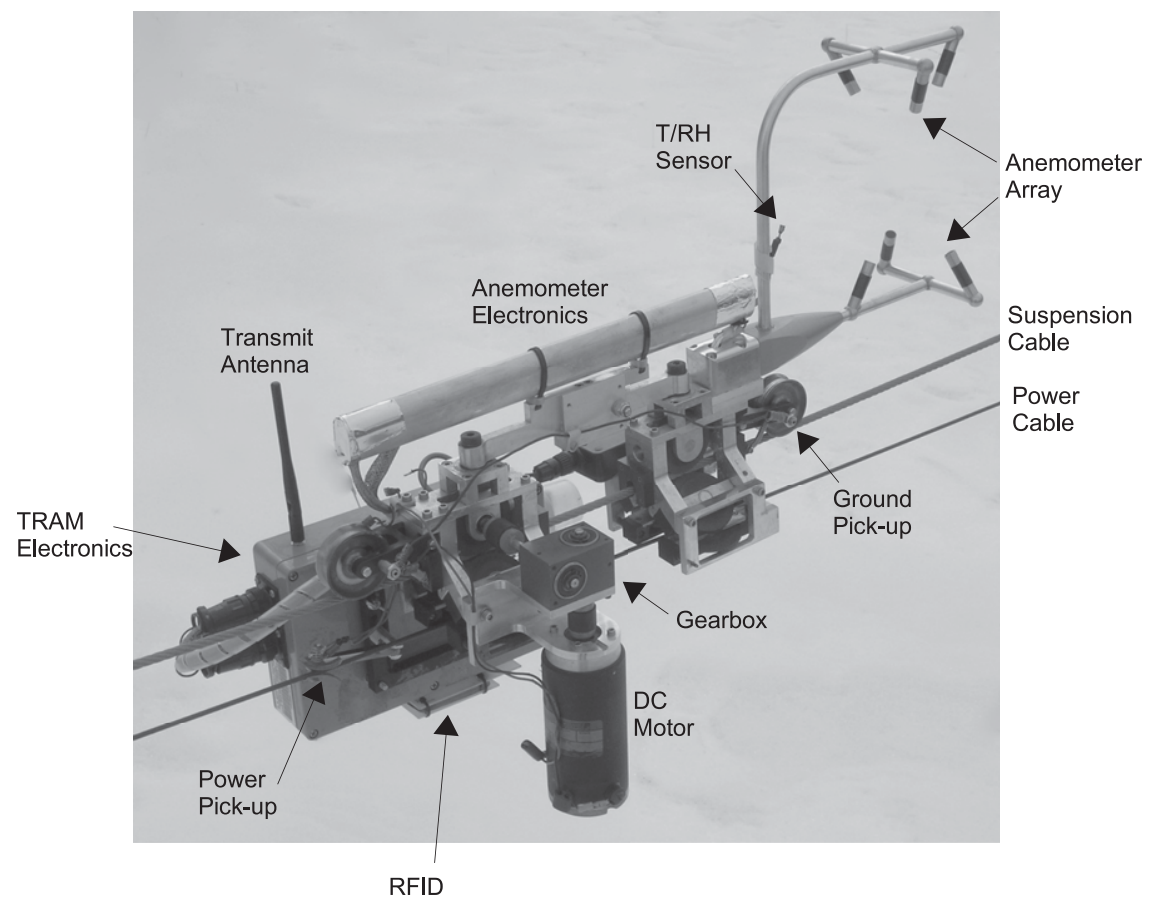

FIG. 2. The TRAM trolley with key components labeled.

along the cable, depending on the inclination. The particular supply we are using has a serial port that allows our data system both to monitor and to control the TRAM power. At present, we have only implemented a "watchdog" function that shuts down all TRAM power if the trolley becomes stuck (detected by the power supply current not changing); however, we could use this functionality to supply more power to the trolley to get it through parts of the track with greater drag. The supply also has the ability to run in conjunction with several identical supplies that could be distributed along extremely long tracks if the power drop due to electrical resistance became too large. With the present track length of $240 \mathrm{~m}$, this drop appears to be negligible.

The choice of the trolley speed is influenced by several factors. For sampling, lower speeds produce greater spatial resolution of the data (given a fixed temporal sampling rate of the sensors) whereas higher speeds reduce the time between repeat samples at each location. Mechanically, the motor needs to provide enough torque to overcome the friction of the turns (which have suspension tubing that necessarily are larger in diameter than the suspension cable and also have the alignment flange that engage an additional set of wheels). This amount of torque results in speeds along the cable of about $2 \mathrm{~m} \mathrm{~s}^{-1}$. The upper limit in speed is limited by the mechanical shock that the trolley experiences when encountering this additional drag during transitions from the cable to the turn. For speeds in excess of about $8 \mathrm{~m} \mathrm{~s}^{-1}$, this shock is enough to physically break components of the trolley in a short amount of time. Extremely careful adjustment of the turns and track layout could produce somewhat faster speeds; however, adding multiple trollies on the same track is seen as a better approach to increase TRAM sampling. Alternately, the motor voltage could be set differently for the turn and cable segments to achieve a wider range of operating speeds. For this study, the trolley speed averaged about $4 \mathrm{~m} \mathrm{~s}^{-1}$ along the cable segments, producing a sampling resolution of $0.4 \mathrm{~m}$ and a repetition period of about $90 \mathrm{~s}$.

\section{c. Sensors}

The sensor complement for TRAM is intended to be flexible to accommodate a wide variety of applications. Since the first use of TRAM was to study advection, measurements of carbon dioxide and wind were required along with temperature and humidity. To avoid making the first trolley too large, sensors were chosen to be relatively small and light.

Most research-quality $\mathrm{CO}_{2}$ sensors were determined to be too bulky for use on TRAM. We chose to use the RMT Ltd. DX6100 closed-path (single cell) infrared gas analyzer, which is only $100 \mathrm{~mm} \times 86 \mathrm{~mm} \times 35 \mathrm{~mm}$ and weighs $276 \mathrm{~g}$. The noise level in $\mathrm{CO}_{2}$ is specified to be 3 $\mu \mathrm{mol} \mathrm{mol}{ }^{-1}$ at 5 samples s$^{-1}$, which is somewhat large. We operated this sensor at 10 samples s $^{-1}$ and thus have 
even more noise. However, the intent of the advection study is to identify pools of $\mathrm{CO}_{2}$ with rather large concentrations $\left(10-100 \mu \mathrm{mol} \mathrm{mol}^{-1}\right.$ higher than ambient) and a modest amount of averaging is possible. (For more accurate measurements we would change to a different analyzer.) Air was brought into the DX6100 using a small pump (KNF-NMP05) attached through a $25-\mathrm{ml}$ buffer volume to the outlet of the analyzer.

Again, because of size and weight limitations, reference gases that are commonly used to calibrate closedpath gas analyzers were not used, despite a modest amount of gain and offset drift that is known for the DX6100 (Goyea 2003). Instead, this sensor was calibrated in situ by comparison to the NCAR Trace Gas Measurement System (TGaMS) (Burns et al. 2009) that has 18 spatially distributed inlets connected to a LICOR LI-7000 infrared gas analyzer that was continually calibrated against four secondary standard gases. Six of these inlets were placed on TRAM towers with two towers-numbered towers 4 and 9-having inlets at the two TRAM cable heights. (The other inlets were placed to map out the along-Como Creek variation of $\mathrm{CO} 2$.) The basic output of the DX6100 is the ratio $D$ of the amount of light in a $\mathrm{CO}_{2}$-absorbing infrared band (4.3 $\mu \mathrm{m})$ to that in a nonabsorbing reference band $(3.9 \mu \mathrm{m})$.

Two estimates of the gain $(G)$ of the DX6100 could be obtained during the half-hour that it took TGaMS to cycle through sampling each of its inlets. Each estimate was calculated as

$$
G=\frac{C\left(t_{1}\right)-C\left(t_{2}\right)}{D\left(t_{1}+d t_{1}\right)-D\left(t_{2}+d t_{2}\right)},
$$

where $C$ was the $\mathrm{CO}_{2}$ concentration measured by TGaMS, $t_{1}$ and $t_{2}$ were the times that TGaMS sampled the inlet at the two heights of either tower 4 or 9 , and $d t_{1}$ and $d t_{2}$ were time offsets to select the nearest time when the trolley passed the TGaMS inlet. The gain was assumed to be constant, so the averages of all of these estimates for all the TRAM data were used. The value thus determined was within $10 \%$ of the manufacturer's calibration.

The offset was determined as $C\left(t_{i}\right)-G D\left(t_{i}+d t_{i}\right)$, where $t_{i}$ and $d t_{i}$ are as $t_{1}$ and $d t_{1}$ above, but for each of the six inlets common to TRAM locations. These values were found to have large-amplitude temporal variations, presumably due to temperature changes that affect the response of the DX6100. The offset was applied to the DX6100 measurements by linearly interpolating between the TGaMS comparison times. Because of the assumption of gain stability and the need to interpolate and sometimes extrapolate from TGaMS measurements, this procedure resulted in concentrations that are only accurate to $10 \%$. However temporal and spatial differences from TRAM should also be within $10 \%$.

Measurement of wind, $\mathbf{u}$, from any moving platform is a combination of determining the air motion relative to the platform $\mathbf{u}_{m}$ and subtracting the platform motion relative to the earth $\mathbf{u}_{p}$ (e.g., Lenschow 1986):

$$
\mathbf{u}=\mathbf{u}_{m}-\mathbf{u}_{p} .
$$

We chose to use a sonic anemometer to measure the wind relative to TRAM because of its good performance in low wind conditions. We constructed our own transducer array to minimize both internal flow distortion and weight, based on the "UW" design of Zhang et al. (1986) and mounted it on top of the front wheel cluster. We were forced to reduce the pathlength from $0.20 \mathrm{~m}$ used by Zhang et al. to $0.15 \mathrm{~m}$ because the torque on the array while the trolley moved through turns deformed the array. This change increases the amount of flow distortion due to wakes from the anemometer transducers (that have a diameter of $0.01 \mathrm{~m}$ ); however, Kaimal et al. (1990) describe another array with a pathlength-to-transducer diameter ratio of 15:1 that is in commercial production. Data from this sensor were recorded at 10 samples $\mathrm{s}^{-1}$. Distortion of the airflow (and thus error in the wind measurement) by the array itself is known to be large for winds coming from behind this type of array. Thus, the trolley must move faster than the wind to keep the relative wind direction ahead of the array. Since previous tower data showed that the in-canopy flow rarely exceeded $1 \mathrm{~m} \mathrm{~s}^{-1}$ (and never exceeded $2 \mathrm{~m} \mathrm{~s}^{-1}$ ) and the nominal trolley speed is 3-5 $\mathrm{m} \mathrm{s}^{-1}$, array flow distortion was not expected to be a problem.

We examined the distortion of the flow by the entire trolley, including the electronics box and motor, by running the trolley in the NCAR wind tunnel (Baynton 1972) through a modest range of azimuth angles. Figure 3 shows that all of the measurements had speed reductions of less than $3 \%$ (except for one value at $3 \mathrm{~m} \mathrm{~s}^{-1}$ that we cannot explain), which is comparable to the level of flow distortion that has been found for the array itself. Furthermore, wind tunnel estimates (at low Reynolds numbers) of flow distortion are usually found to overestimate the magnitude of what occurs in a real, turbulent flow (see e.g., Högström and Smedman 2004). Thus, no correction for flow distortion was applied.

The sonic anemometer data taken during this project had continuous noise while the trolley was moving, which became more frequent later in the study. Our current hypothesis is that loose connections inside the anemometer's transducers made intermittent contact due to vibration. Unfortunately, this problem was not 


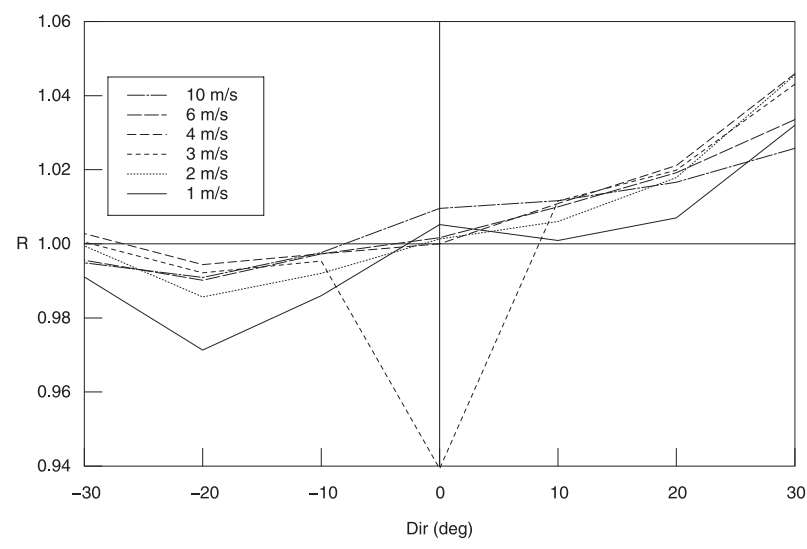

FIG. 3. The ratio $R$ of the wind speed measured by the trolley to the speed of the wind tunnel for a range of tunnel speeds and a small range of relative wind directions. This ratio has also been normalized by the ratio at $4 \mathrm{~m} \mathrm{~s}^{-1}$ and $0^{\circ}$. For a direction of $0^{\circ}$, the wind is into the trolley along its the longitudinal axis (the direction of the suspension cable).

resolved in the field. However, removing anemometer data when the $v_{m}$ and $w_{m}$ components or acoustic temperature, $t_{c}$, were obviously bad $\left(\left|v_{m}\right|>2 \mathrm{~m} \mathrm{~s}^{-1}\right.$; $\left|w_{m}\right|>1 \mathrm{~m} \mathrm{~s}^{-1} ; t_{c}$ not between $-10^{\circ}$ and $\left.40^{\circ} \mathrm{C}\right)$, left approximately $78 \%$ of the data that appeared to be reasonable.

Determining the trolley motion was a harder problem than anticipated. The trolley has a GPS receiver, but GPS reception inside the canopy was poor and $70 \%$ of the time no satellites were available. Even with good reception, GPS data reporting at 1 sample $\mathrm{s}^{-1}$ is too slow for TRAM, since it typically dwelled on either a turn or cable segment for only $1-5 \mathrm{~s}$. The trolley also carried a three-axis fluxgate compass (Honeywell HMR3300) attached to the front wheel cluster that reported the heading, pitch, and roll angles of the sonic anemometer to $0.1^{\circ}$ resolution at the same data rate as the anemometer. We plan to add a counter to one of the trolley's wheels (similar to a bicycle speedometer), but this had not been done for the present study. Thus, we have simply used the difference in time for the trolley to go between known positions. However, knowing the trolley position has also not been easy. By the end of the study, we set the TRAM power supply to report its voltage and current use at 8 samples $\mathrm{s}^{-1}$ and we had found that a large increase in current was a good indicator of when the trolley was in a turn. Radio-frequency identification (RFID) markers were also being read at several of the towers to identify exactly when the trolley passed certain towers. (The markers we used only read reliably when the trolley was moving slowly, so some turns were never scanned. Different markers will be tried in the future.) However, at the beginning of the study neither of these signals was available. Thus, we used the reported trolley heading to determine trolley position. The fluxgate compass signal apparently was affected by the steel towers that were used to support the turns, so the data contained numerous spikes and sometimes drifted even while the trolley was along a straight cable segment. Nevertheless, reasonable position estimates were obtained by correlating the heading signal with an ideal signal synthesized from knowledge of the tower positions surveyed using a differential GPS system. These position estimates generally agreed to within $1 \mathrm{~m}$ of the RFID positions. With these estimates of the times when the trolley entered and exited each turn, the average speed along each track segment (cable or turn) could be calculated.

With the knowledge of $u_{p}$, the ground-referenced wind can be calculated from Eq. (2), starting with

$$
\mathbf{u}_{p}=u_{p} \mathbf{i}
$$

thus,

$$
(u, v, w)=\left(u_{m}-u_{p}, v_{m}, w_{m}\right)
$$

in trolley coordinates. This equation assumes that the trolley heading is aligned with the cable azimuth, which is a reasonably good assumption, but could be corrected since both measurements are available. This equation also assumes that the cable is fixed, which is not strictly correct. However, the cable appears to move at most a few centimeters sideways and vertically at frequencies lower than $3 \mathrm{~Hz}$, mostly because of vibration. Thus, the instantaneous $v_{p}$ and $w_{p}$ should be less than $0.1 \mathrm{~m} \mathrm{~s}^{-1}$ and averages of $v_{p}$ and $w_{p}$ over several vibration cycles (say 2 s) should be nearly zero. To convert from trolley coordinates to earth-referenced coordinates, the winds need to be multiplied by a rotation matrix calculated for every sample based on the measured heading, pitch, and roll of the trolley. This has not yet been done, because of the compass errors noted above, but will when a better attitude measurement is available.

Temperature and relative humidity were measured by an SHT75 solid-state sensor deployed near the sonic anemometer. The SHT75 can only be sampled at 2 samples $\mathrm{s}^{-1}$ before self-heating errors become large, but this is fast enough to resolve many of the spatial features described below. Data from this sensor also were somewhat noisy-probably a data transmission issue_-but were readily despiked.

\section{d. Data system}

A simple 8/16-bit microprocessor (PIC18F252) acquired data from the above instrumentation. Five discrete serial ports (UARTs) were attached to this 
processor to receive data from the anemometer, $\mathrm{CO}_{2}$ analyzer, RFID reader, fluxgate compass, and GPS receiver. Digital I/O lines on the PIC read the T/RH sensor. PIC analog inputs initially were set up to monitor the trolley power and a future photosynthetically active radiation (PAR) sensor, but were later removed to minimize contamination of the sonic anemometer electronic signal.

When a complete sample was received from any sensor, it was retransmitted through a sixth UART that is part of the PIC. This UART was connected to a 2.4$\mathrm{GHz}$ radio modem that was configured for point-topoint communication to an identical modem attached to a fixed NCAR data system. This radio link allowed realtime monitoring and archiving of all TRAM data without complicating the mechanical design.

A final feature of the data system was control of the trolley power using a solid-state relay. The signal to command this relay could be sent by the operator through the radio link to the trolley. At present, this capability has been only used to stop the trolley while keeping the data system running (e.g., to allow time for the GPS receiver to acquire satellites). However, it is envisioned that this capability could allow multiple trollies to operate along the same track while maintaining a constant separation.

\section{Deployment}

The first field deployment of TRAM was part of a study at Niwot Ridge during the summer and fall of 2007 (NIWOT07). Within a 1-km radius, the slope at this site is relatively uniform, with a slope of about $6^{\circ}$, falling to the east (Fig. 4). The entire slope is drained by Como Creek, which is about $2 \mathrm{~m}$ across, and is fed by seasonal smaller drainages as the winter snow melts. The vegetation is mostly lodgepole pine (height about $11 \mathrm{~m}$ ), with fir and spruce also present. There are some small groves of aspen and shrubs, especially near the creek. See Monson et al. (2002) and Turnipseed et al. (2002) for more details about this site.

The TRAM transect crossed Como Creek. A loop was formed by having the trolley travel south at $5 \mathrm{~m}$ above ground (nominally in the middle of the canopy), make a $180^{\circ}$ turn, return along the same set of towers heading north at $1 \mathrm{~m}$ above ground (nominally the trunk space), then turn $180^{\circ}$ again. The transect was approximately $120 \mathrm{~m}$ long, forming a $240-\mathrm{m}$ total loop. The transect crossed Como Creek about $40 \mathrm{~m}$ south of the northern tower.

Several other sensor systems were deployed near the TRAM transect during this period. The TGaMS system used to measure larger-scale $\mathrm{CO}_{2}$ gradients has been mentioned above. The other sensors used here were a set of 3D sonic anemometers (similar to Zhang et al. 1986) deployed on the TRAM tower nearest Como Creek. These anemometers were used to check the TRAM wind measurements (see below).

The trolley drive wheel has been found to slip and can eventually be destroyed when the track is wet. Thus, we only operate TRAM in dry conditions (which also avoids any sensor issues in rain). However, rain often occurs in the afternoon in the Colorado mountains during the summer. Also, the trolley occasionally stopped moving for a variety of reasons (some yet unknown). Usually, the stoppage was due to a part of the track becoming slightly misaligned and restarting was simple. At times, we deliberately stopped the trolley to resolve sensor problems that showed up in our real-time data monitoring. Therefore, during NIWOT07 an operator monitored TRAM at all times. This, along with the weather, limited the amount of data that were collected. Future plans for TRAM are to make it more robust by parking the trolley when rain is detected (by a wetness indicator), continuing work to improve the process of setting up the track, and replacing some connectors.

Nevertheless, during August and September 2007 almost $60 \mathrm{~h}$ of data were collected during 12 outings. The trolley typically completed a lap in $90 \mathrm{~s}$, so more than 2000 laps around the track were sampled. These data were taken at various times of the day and night, so that every hour of the diurnal cycle was sampled on two-six outings. The longest outing was about $12 \mathrm{~h}$ and the longest continuous run was almost $4 \mathrm{~h}$.

\section{Results}

As NIWOT07 was TRAM's first deployment, there were problems with each of its sensors at one time or another. However, several features of this dataset can be shown.

An example time series from TRAM is shown in Fig. 5 over about three laps along the transect. Clearly, the data are periodic. In this example during the night of 17 August, $\mathrm{CO}_{2}$ concentrations become almost $80 \mu \mathrm{mol}$ $\mathrm{mol}^{-1}$ higher during the few seconds when the trolley was sampling near Como Creek at the 1-m height than anywhere else along the track. (This case was the largest $\mathrm{CO}_{2}$ gradient observed by TRAM.) A secondary maximum appears when the trolley crosses the creek at $5 \mathrm{~m}$. Specific humidity $q$ varies similarly to $\mathrm{CO}_{2}$ and temperature $T$ is generally anticorrelated with both $q$ and $\mathrm{CO}_{2}$. This is a consistent pattern as seen in Fig. 6, which shows 2-hourly averages of $\mathrm{CO}_{2}$ concentration as a function of track position for this night. Note that during the day $\mathrm{CO}_{2}$ appears to be well mixed and no change 


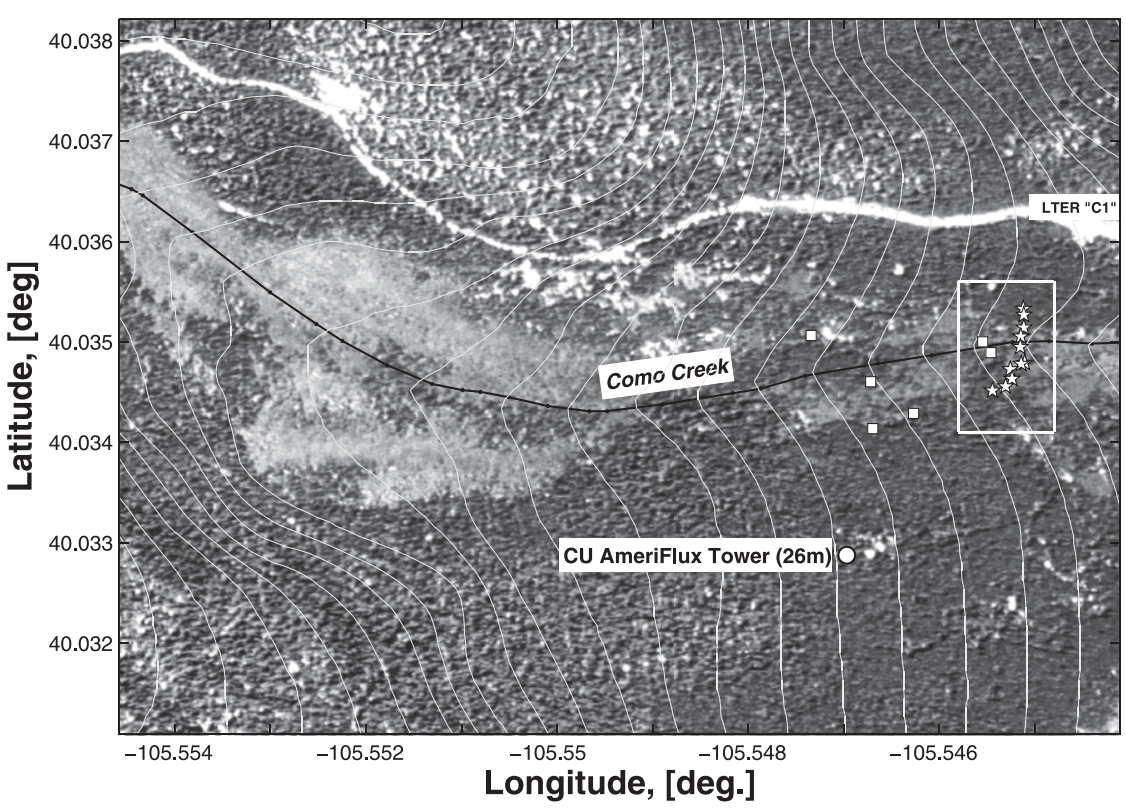

FIG. 4. Image of the region near the Ameriflux site at Niwot Ridge. The 11 TRAM towers are shown as stars inside a box on the right. The six additional TGaMS inlet locations are shown as boxes to the west of the TRAM towers. The lighter areas on the left side of the image indicate marsh regions, whereas most of the rest of the image is coniferous forest. The thick white curve near the top of the image is the site access road. The area shown is $1100 \mathrm{~m}$ by $800 \mathrm{~m}$ and the terrain contour interval is $5 \mathrm{~m}$, with the CU Ameriflux tower at $3049 \mathrm{~m}$ MSL.

along the track is observed. This signature-well-mixed $\mathrm{CO}_{2}$ during the day and a buildup at the creek at night - was seen consistently in all of the TRAM data and agrees with observations taken in 2004 at this site (Burns et al. 2006).

Figure 7 presents a subset of the data from this night as a time-distance cross section. Clearly, the placement of the maximum $\mathrm{CO}_{2}$ concentration at the Creek seen in Fig. 6 is an artifact of temporal averaging. Figure 7e shows that "blobs" of $\mathrm{CO}_{2}$-rich air concentrate close to the surface (1-m height) in the general vicinity of the creek, though their exact position shifts with time, more-or-less following the wind trajectory. These blobs appear to be on the order of $20 \mathrm{~m}$ wide, $100-600 \mathrm{~m}$ long, and mostly less than $5 \mathrm{~m}$ high. The relatively large temporal changes in amplitude show that the transport of $\mathrm{CO}_{2}$-rich air by land breezes described by Sun et al. (1998) can be a discontinuous process. A clear relation between the finescale structure of these blobs and the (three dimensional) wind velocity is not apparent, suggesting that turbulent mixing does not control how they are organized, though see below for a larger-scale effect.

Figures $7 d$,f show that these blobs are generally cool and moist, though there is not a perfect correlation between the spatial variations of these three scalar quantities. The general correlation seen between $\mathrm{CO}_{2}$ and $q$ was observed during all of the nocturnal outings. The relatively finescale structure seen in the fields of $\mathrm{CO}_{2}$ concentration and $q$ are not observed in temperature. The time constant of the temperature sensor was a few seconds, which could smooth out some of the detail seen in the other signals, but temperature from the sonic anemometer (not shown here due to data glitches) also did not show much finescale structure.

Finally, Fig. $7 \mathrm{~b}$ shows that the $\mathrm{CO}_{2}$ concentrations were much lower at night in the midcanopy space just 4 $\mathrm{m}$ higher than the data shown in Fig. 7e. This behavior has been observed by others at this site. The blobs that have the greatest $\mathrm{CO}_{2}$ concentration at $1 \mathrm{~m}$ appear to extend vertically up to $5 \mathrm{~m}$, whereas a lesser-amplitude blob at 2320 MDT in the 1-m data does not appear at 5 $\mathrm{m}$. Again, $\mathrm{CO}_{2}$ concentration and $q$ appear to be moreor-less correlated and $\mathrm{CO}_{2}$ and $T$ are vaguely anticorrelated.

Figure 8 presents a longer duration case in which a similar pattern of meandering blobs of $\mathrm{CO}_{2}$ disappeared at $0240 \mathrm{MDT}$ in a matter of minutes with the pattern reappearing about $4 \mathrm{~h}$ later. This change is associated with a shift in wind direction (from $270^{\circ}$ to $295^{\circ}$ ), a doubling of wind speed (from 0.5 to $1.0 \mathrm{~m} \mathrm{~s}^{-1}$ ), and a factor of 3 increase in the variance of $w$ (from 0.003 to $0.011 \mathrm{~m}^{2} \mathrm{~s}^{-2}$ ) during this 4 -h period. Thus, the decrease 

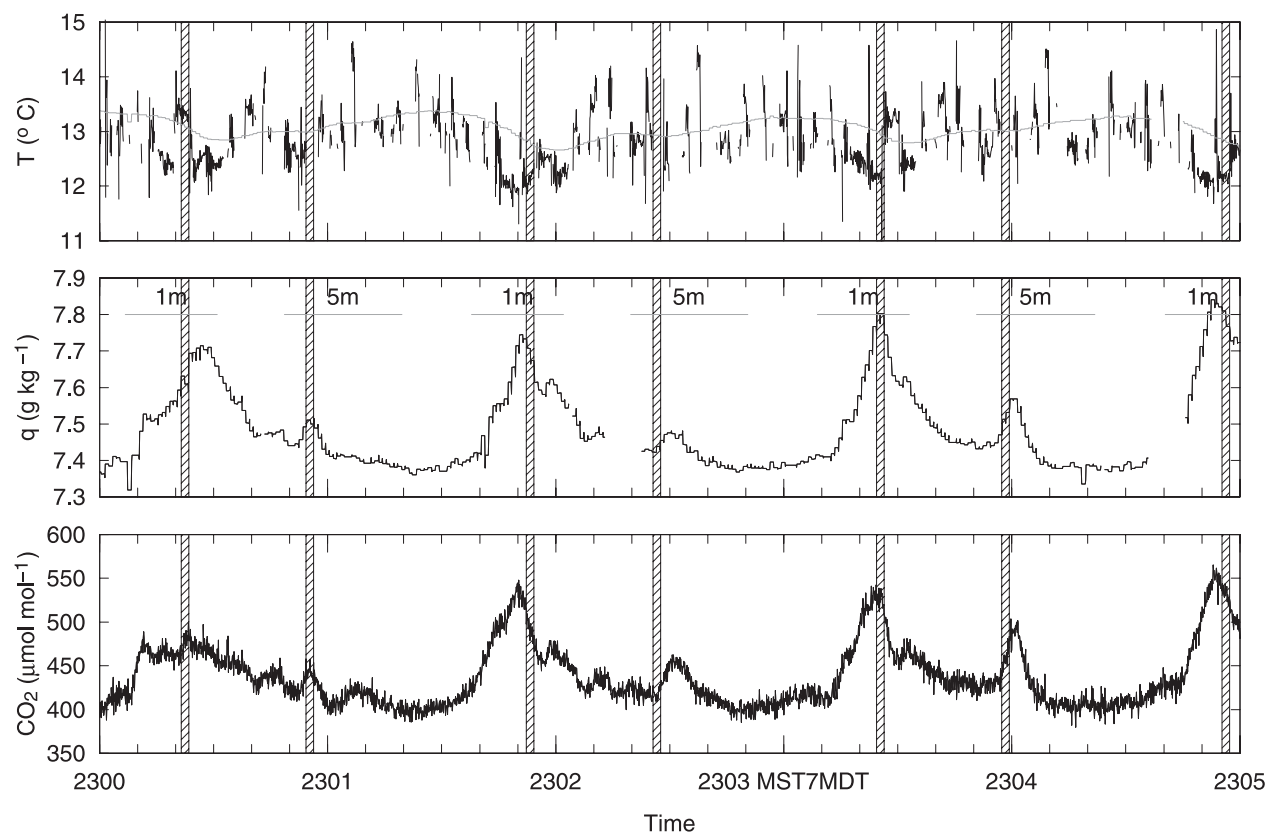

FIG. 5. Example time series of (top) temperature, (middle) specific humidity, and (bottom) carbon dioxide concentration from TRAM. Temperature data are shown from both the slow-response sensor (dotted line) and the sonic anemometer (solid line, with gaps during the turns). Cross hatching indicates when the trolley was over Como Creek. The (middle) also shows when the trolley was at 1 and $5 \mathrm{~m}$.

of $\mathrm{CO}_{2}$ during these $4 \mathrm{~h}$ is due either to enhanced vertical mixing (which would transport $\mathrm{CO}_{2}$ to higher levels of the canopy or above) or to horizontal advection of air with lower $\mathrm{CO}_{2}$ concentration (or both). Figure 4 shows that for the west winds before and after this period air would have come from a wetland $400 \mathrm{~m}$ to the west of the TRAM location. Wetlands generally are assumed to have relatively high respiration rates due to higher amounts of soil organic matter, though we have no data that verifies this assumption and the $\mathrm{CO}_{2}$ flux to the

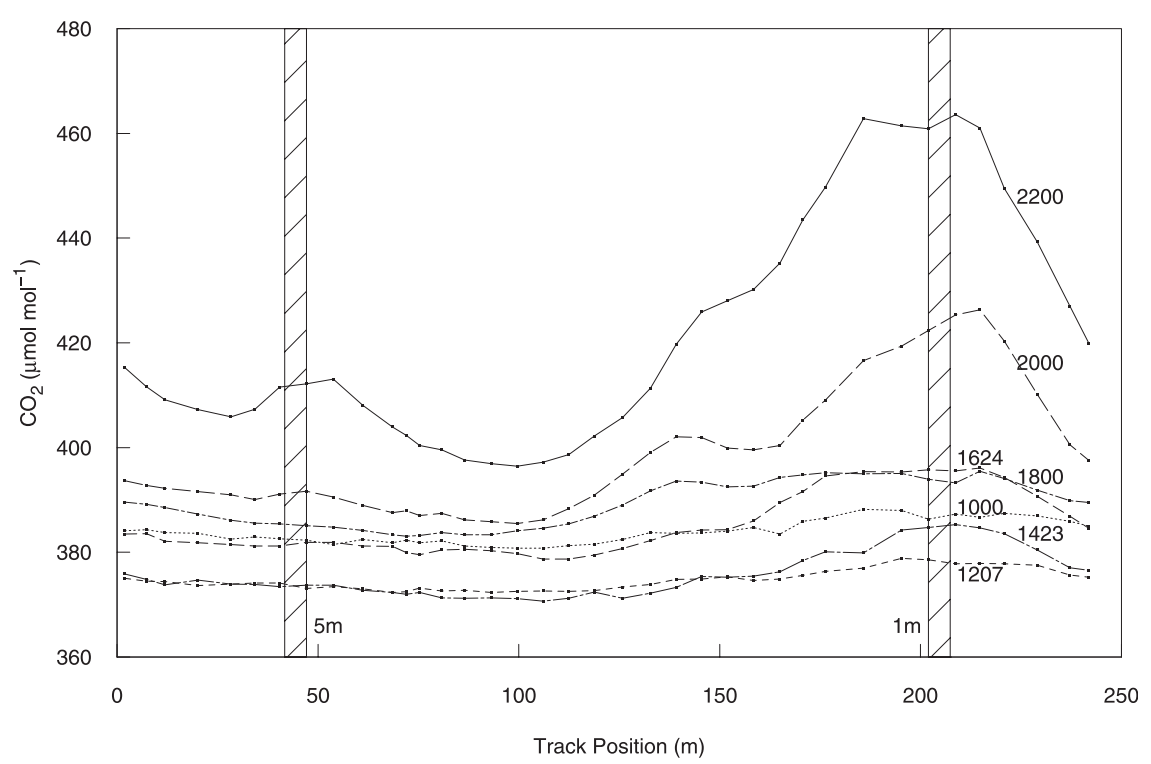

FIG. 6. Composites of TRAM CO 2 data for the outing on $17 \mathrm{Aug}$, with values averaged over 2-h periods for each position along the track. Line labels are the start time (MDT) of each period. Track positions $0-127 \mathrm{~m}$ are for the trolley traversing southward at a height of $5 \mathrm{~m}$ and $127-245 \mathrm{~m}$ for the northward return at $1 \mathrm{~m}$. As with Fig. 5, cross hatching indicates Como Creek. 

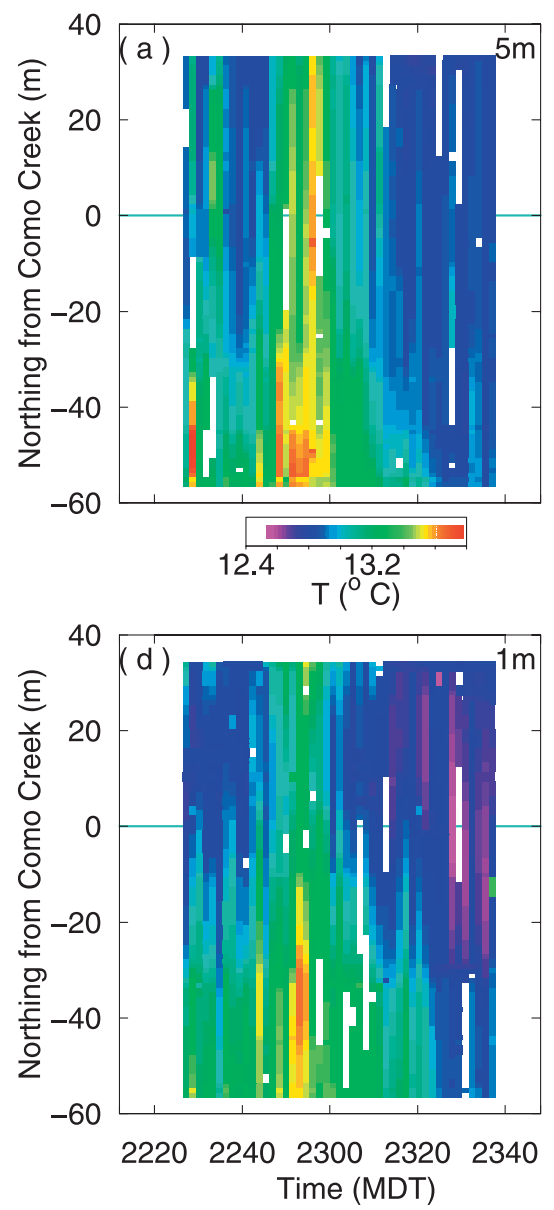
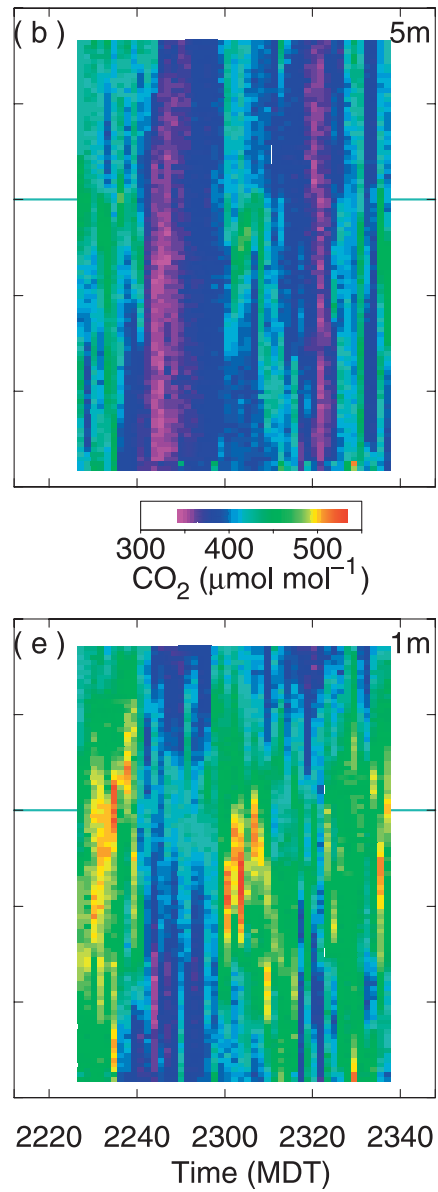
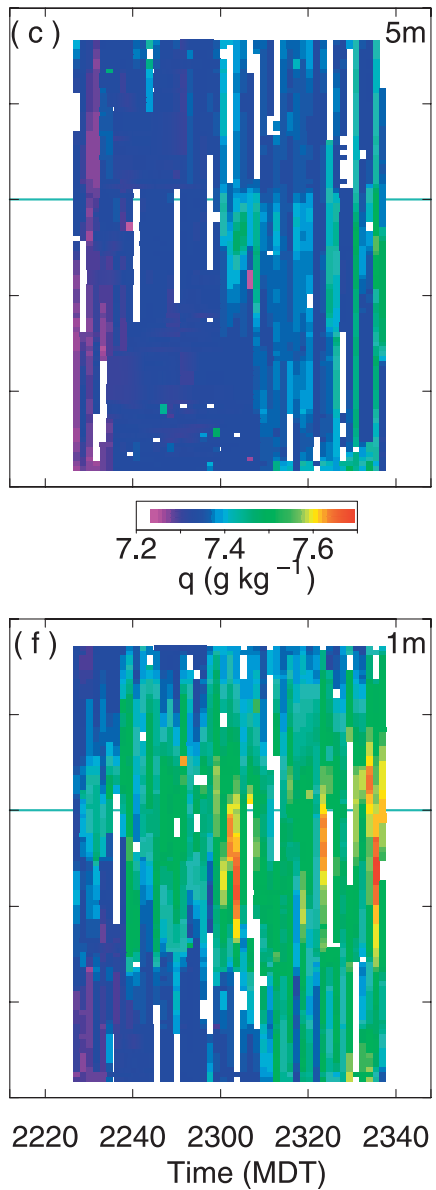

FIG. 7. Time-distance cross sections of (a),(d) temperature $T$; (b),(e) carbon dioxide concentrations $\mathrm{CO}_{2}$; and (c),(f) specific humidity $q$ measured by TRAM. Distances are the position north of Como Creek. (The creek is indicated by the horizontal blue line.) Measurements made at a height of (a)-(c) $5 \mathrm{~m}$ and at (d)-(f) $1 \mathrm{~m}$. Values have been averaged over $1 \mathrm{~m}$ of this distance. Each trolley circuit produces a vertical stripe.

atmosphere likely is different because of the lack of a tall canopy. For more northerly wind directions, the fetch is from the slope of Niwot Ridge itself where soils would be expected to have less organic matter. If advection is dominant, much of the nocturnal $\mathrm{CO}_{2}$ buildup that was observed would not be from local sources.

A comparison of TRAM wind measurements with the nearest fixed anemometer is shown in Fig. 9 for the outing on 7-8 September. This case was selected since the anemometer performance degraded with time, but prior to this date the power supply readings (needed to determine trolley speed) were sampled only at a low data rate. Each point in this figure is the median of $1.8 \mathrm{~s}$ of data (about $7 \mathrm{~m}$ of distance) as the trolley was approaching the fixed anemometer. During this period, the trolley would have been on the low cable segment over Como Creek itself. The wind components are presented in trolley coordinates, so the $v$ component is simply the measurement from TRAM's anemometer whereas the $u$ component also includes the derived trolley motion [Eq. (4)].

An offset of about $0.6 \mathrm{~m} \mathrm{~s}^{-1}$ is seen in $u$. The most obvious explanation for this offset would be an error in the determination of the trolley speed, however the values that were used (that averaged $3.7 \mathrm{~m} \mathrm{~s}^{-1}$ ) appear to be reasonable given the measured times passing known positions. Thus, we suspect that this represents a "cycle-slip" due to mistriggering of a weak transducer and/or the aforementioned loose connection in the sonic anemometer for this path while the trolley was in motion. (Data taken on this night when the trolley was not moving did not show this offset.) The scatter in the data (with a standard deviation of about $0.12 \mathrm{~m} \mathrm{~s}^{-1}$ for each component) presumably represents real differences due to the different sampling in space, though the measured trolley motion contained in $u$ also has an uncertainty of about this magnitude. 

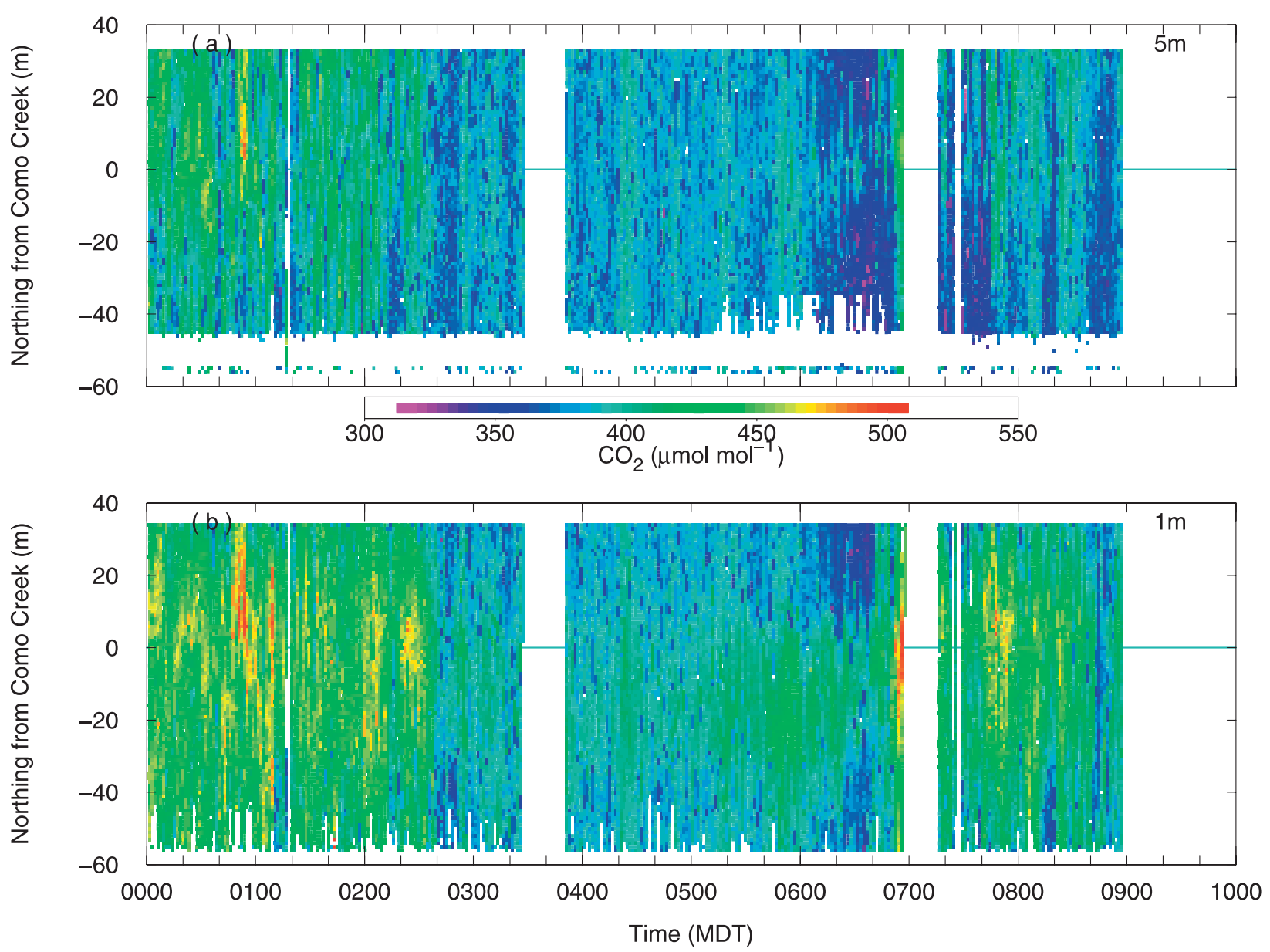

FIG. 8. As in Fig. 7, but for values of $\mathrm{CO}_{2}$ concentration for the morning of $8 \mathrm{Sep}$. Missing data at the bottom of (a) and to a lesser extent in (b) are due to a loose antenna connection on this day.

\section{Summary and future work}

We have constructed a new tool for measuring especially horizontal gradients of atmospheric variables over spatial scales of 1-100 m and temporal scales on the order of minutes. The variables currently measured are wind velocity, temperature, humidity, and $\mathrm{CO}_{2}$ concentration. In our initial use of TRAM, most measurements had problems at least some of the time for a variety of reasons. We are currently working to resolve these issues.

The variation of $\mathrm{CO}_{2}$ that was found is consistent with tower-based observations made previously at this site, however the limited spatial extent had previously been unknown. Future work will calculate a $\mathrm{CO}_{2}$ budget for the area by synthesizing TRAM observations with the soil respiration, TGaMS $\mathrm{CO}_{2}$ gradient, and tower $\mathrm{CO}_{2}$ flux and concentration observations made at this site during the same period. However, the spatial placement of these measurements was not optimal in 2007, so some level of spatial homogeneity will need to be assumed. TRAM will be redeployed closer to the University of Colorado AmeriFlux tower in 2008, among other reasons to enable a budget calculation with fewer assumptions.

Finally, we plan to add sensors for photosynthetically active radiation (PAR), ozone, and aerosol size distribution to allow TRAM to be used for other applications.

Acknowledgments. Construction of TRAM would not have been possible without the support of the NCAR Design and Fabrication Services Facility. Deployment of TRAM was supported by several staff with the NCAR In-Situ Sensing Facility and by students and staff in the University of Colorado Department of Ecology and Evolutionary Biology. Lynette Laffea, in particular, surveyed the TRAM tower locations used in the position calculation. The NCAR Biogeosciences Initiative, which is now part of The Institute for Integrative and 


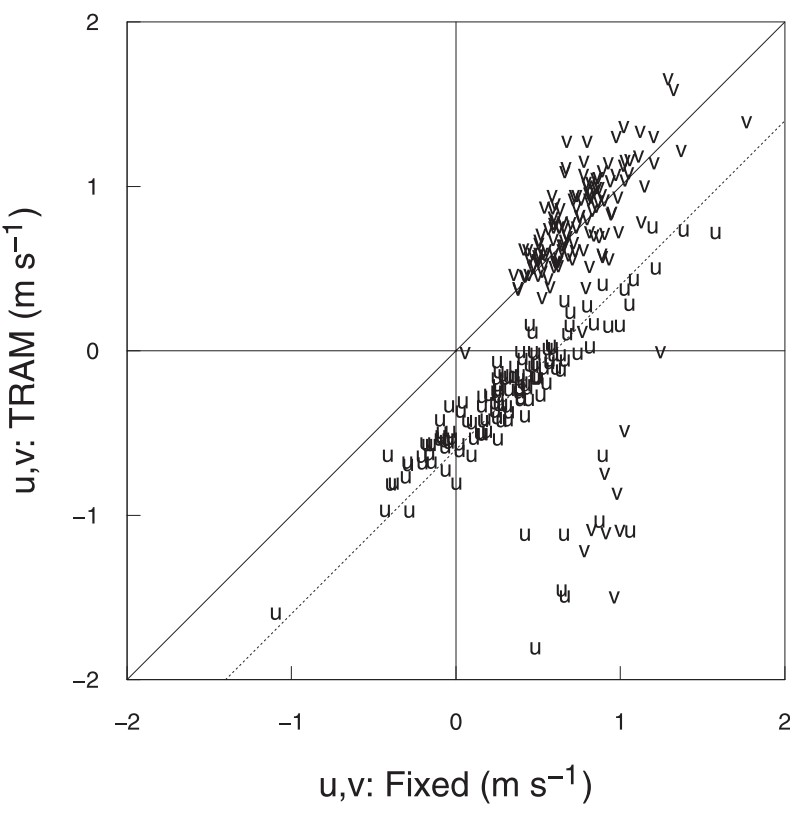

FIG. 9. Comparison of wind measurements from TRAM vs those made by a fixed sonic anemometer. The dotted reference line indicates an offset of $0.6 \mathrm{~m} \mathrm{~s}^{-1}$.

Multidisplinary Earth Studies (TIIMES), provided much of the funding for the construction of TRAM. Further funding for the deployment of TRAM at Niwot Ridge was provided by the National Science Foundation (Award DBI-0528793). Any opinions, findings and conclusions or recommendations expressed in this publication are those of the authors and do not necessarily reflect the views of the National Science Foundation.

\section{REFERENCES}

Baldocchi, D., B. Hutchison, D. Matt, and R. McMillen, 1984a: Seasonal variations in the radiation regime within an oakhickory forest. Agric. For. Meteor., 33, 177-191.

_ , D. R. Matt, B. A. Hutchison, and R. T. McMillen, 1984b: Solar radiation within an oak-hickory forest: An evaluation of the extinction coefficients for several radiation components during fully-leafed and leafless periods. Agric. For. Meteor., 32, 307-322.

Baynton, H. W., 1972: NCAR wind tunnel. Facilities for Atmospheric Research, No. 20, National Center for Atmospheric Research/Facilities Laboratory, 22-24.

Blanken, P. D., T. A. Black, H. H. Neumann, G. den Hartog, P. C. Yang, Z. Nesic, and X. Lee, 2001: The seasonal water and energy exchange above and within a boreal aspen forest. $J$. Hydrol., 245, 118-136.

Burns, S. P., and Coauthors, 2006: Measurements of the diurnal cycle of temperature, humidity, wind, and carbon dioxide in a subalpine forest during the Carbon in the Mountains Experiment (CME04). Preprints, 17th Symp. on Boundary Layers and Turbulence, San Diego, CA, Amer. Meteor. Soc., JP4.7.
[Available online at http://ams.confex.com/ams/pdfpapers/ 110188.pdf.]

and Coauthors, 2009: An evaluation of calibration techniques for in situ carbon dioxide measurements using a programmable portable trace-gas measuring system. J. Atmos. Oceanic Technol., in press.

Chen, J. M., P. D. Blanken, T. A. Black, M. Guilbeault, and S. Chen, 1997: Radiation regime and canopy architecture in a boreal aspen forest. Agric. For. Meteor., 86 (1-2), 107-125.

Dabberdt, W. F., 1968: Tower-induced errors in wind profile measurements. J. Appl. Meteor., 7, 359-366.

Gamon, J. A., Y. Cheng, H. Claudio, L. MacKinney, and D. A. Sims, 2006: A mobile tram system for systematic sampling of ecosystem optical properties. Remote Sens. Environ., 103, $246-254$

Goyea, O., 2003: Testing and modification of two infrared gas analyzers for $\mathrm{CO} 2$ Measurement. National Center for Atmospheric Research/SOARS, Boulder, CO, 22 pp.

Högström, U., and A.-S. Smedman, 2004: Accuracy of sonic anemometers: Laminar wind-tunnel calibrations compared to atmospheric in situ calibrations against a reference instrument. Bound.-Layer Meteor., 111, 33-54.

Kaimal, J. C., J. E. Gaynor, H. A. Zimmerman, and G. A. Zimmerman, 1990: Minimizing flow distortion errors in a sonic anemometer. Bound.-Layer Meteor., 53, 103-115.

Lee, X., and A. T. Black, 1993: Atmospheric turbulence within and above a Douglas-fir stand. Part II: Eddy fluxes of sensible heat and water vapour. Bound.-Layer Meteor., 64, 369-389.

Lenschow, D. H., 1986: Aircraft measurements in the boundary layer. Probing the Atmospheric Boundary Layer, D. H. Lenschow, Ed., Amer. Meteor. Soc., 39-55.

Miyake, M., and Coauthors, 1970: Comparison of turbulent fluxes over water determined by profile and eddy correlation techniques. Quart. J. Roy. Meteor. Soc., 96, 132-137.

Monson, R. K., A. A. Turnipseed, J. P. Sparks, P. C. Harlen, L. E. Scott-Denton, K. Sparks, and T. E. Huxman, 2002: Carbon sequestration in a high-elevation, subalpine forest. Global Change Biol., 8, 459-478.

Privette, J. L., and Coauthors, 1997: Estimating spectral albedo and nadir reflectance through inversion of simple PRDF models with AVHRR/MODIS-like data. J. Geophys. Res., 102 (D24), 29 529-29 542.

Schimel, D., T. G. F. Kittel, S. Running, R. Monson, A. Turnipseed, and D. Anderson, 2002: Carbon sequestration studied in Western U.S. mountains. Eos, Trans. Amer. Geophys. Union, 83, 445-449.

Singh, A., M. A. Batalin, M. Stealey, V. Chen, M. H. Hansen, T. C. Harmon, G. S. Sukhatme, and W. J. Kaiser, 2008: Mobile robot sensing for environmental applications. Results of the 6th International Conference, C. Laugier and R. Siegwart, Eds., Vol. 42, Field and Service Robotics, Springer, 125-135.

Sun, J., R. Desjardins, L. Mahrt, and I. MacPherson, 1998: Transport of carbon dioxide, water vapor, and ozone by turbulence and local circulations. J. Geophys. Res., 103 (D20), $25873-25885$.

, and Coauthors, 2007: CO2 transport over complex terrain. Agric. For. Meteor., 145, 1-21.

Turnipseed, A. A., P. D. Blanken, D. E. Anderson, and R. K. Monson, 2002: Surface energy balance above a high-elevation subalpine forest. Agric. For. Meteor., 110, 177-201.

Zhang, S. F., J. C. Wyngaard, J. A. Businger, and S. P. Oncley, 1986: Response characteristics of the U. W. sonic anemometer. J. Atmos. Oceanic Technol., 3, 315-323. 